\title{
Experimental Study of Thermo-Physical Characteristics of Molten Nitrate Salts Based Nanof luids for Thermal Energy Storage
}

\author{
Geng Qiao, ${ }^{1}$ Hui Cao, ${ }^{2}$ Feng Jiang, ${ }^{3}$ Xiaohui She, ${ }^{2 *}$ Lin Cong,, Qing Liu, ${ }^{3}$ Xianzhang Lei, ${ }^{1}$ Alessio Alexiadis ${ }^{2}$ and Yulong Ding ${ }^{2}$
}

Thermal energy storage (TES) is popular to shift peak-load, eliminate the intermittency of renewable energy and recover industrial waste heat. Molten nitrate salts are the TES materials widely used in solar power plants. Pure nitrate salts show some unfavourable properties and hence composite salts are usually required. Adding nanoparticles into nitrate salts was reported as a good method to enhance their properties. However, it does not always show positive results and the enhancements are sensitive to a number of parameters. Till now, there is also no a robust theoretical model to explain these phenomena due to the lack of enough experimental data. Hence, more experimental studies are needed for promoting the development of theoretical models. In this paper, three molten nitrate salts based nanofluids are synthesized by doping $\mathrm{SiO}_{2}$ nanoparticles into three popular single salts $\left(\mathrm{NaNO}_{3}, \mathrm{LiNO}_{3}\right.$ and $\left.\mathrm{KNO}_{3}\right)$. Effects of nanoparticle sizes $(15 \mathrm{~nm}-5 \mu \mathrm{m})$, mass fractions $(0.5-4 \%)$ and temperature $\left(200-380{ }^{\circ} \mathrm{C}\right)$ are considered. Thermo-physical properties of the composite materials are tested, including material structure, melting point, latent heat, specific heat capacity and thermal conductivity. Results show that the addition of $\mathrm{SiO}_{2}$ nanoparticles has little effect on melting points of $\mathrm{LiNO}_{3}$ and $\mathrm{KNO}_{3}$, but it increases their latent heat by $\sim 1.7 \%$; for $\mathrm{NaNO}_{3}$, it smelting points are decreased by up to $2.5{ }^{\circ} \mathrm{C}$ while latent heat keeps stable with the reasonable $\mathrm{SiO}_{2}$ nanoparticle size and mass fraction. The specific heat capacities of $\mathrm{NaNO}_{3}$ and $\mathrm{LiNO}_{3}$ are enhanced by $27.6 \%$ and $12.3 \%$ with the addition of $60-70 \mathrm{~nm} 2 \%$ and $0.5 \%$ SiO 2 nanoparticles, respectively; for $\mathrm{KNO}_{3}$, the highest enhancement of $26 \%$ is achieved with $15-20 \mathrm{~nm} 1 \% \mathrm{SiO}_{2}$ nanoparticles. It is surprising to find that the addition of $\mathrm{SiO}_{2}$ nanoparticles leads to a decreased thermal conductivity for all the three nitrate salts, which is probably due to the thermal resistance. This paper provides comprehensive and valuable experimental data, contributing to the development of robust models for predicting the effect of nanoparticles.

Keywords: Thermal energy storage; Nanoparticle; Molten salt; Nanofluid; Renewable energy

Received 25 January 2019, Accepted 9 April 2019

DOI: $10.30919 / \mathrm{esee} 8 \mathrm{c} 225$

\section{Introduction}

Renewable energy is increasingly popular in recent years to combat climate changes and reduce carbon emissions. By 2017, renewable energy accounted for $10.3 \%$ of total global energy consumption for heat. ${ }^{1}$ However, renewable energy is usually intermittent and hence there is a mismatch between energy supply and demand. Thermal energy storage (TES) provides an avenue to eliminate the uncertainty and inconsistency of renewable energy. This is accomplished by storing energy with TES materials at off-peak times when the supply exceeds demands and then releasing energy at peak times or whenever it's needed.

Among different TES materials, molten salts attract much attention as they offer favourable specifications, such as wide melting temperatures of $250-1580{ }^{\circ} \mathrm{C}$, low vaporpressure, low viscosity and good chemical stability. ${ }^{3}$ Nitrate salts, as one kind of molten salts, have been widely used as energy storage medium and heat transfer fluid in

'Global Energy Interconnection Research Institute Europe GmbH, Berlin, 10623, Germany

${ }^{2}$ Birmingham Centre for Energy Storage, University of Birmingham, Birmingham, B15 2TT, UK

${ }^{3}$ University of Science and Technology Beijing, Beijing, 100083, China

*E-mail:X.She@bham.ac.uk solar power plants, such as the 19.9 MW Torresol Gemasolar power tower $^{4}$ and 49.9 MW Andasol power plant in Spain. ${ }^{5}$ In real applications, a composite nitrate salt is used rather than a pure salt. The advantages include enhanced heat transfer, desired melting point, higher energy storage density, etc. A number of methods have been proposed to manufacture various composite nitrate salts to improve their different properties, including form-stable nitrate salts ${ }^{6,7}$ for enhancing heat transfer, microencapsulation ${ }^{8,9}$ to improve thermal stability and avoid corrosivity, multi component nitrate salts ${ }^{10-14}$ for lowering melting points, molten salt based nanofluids ${ }^{15-33}$ to improve energy storage density, etc.

Molten salt based nanofluid was prepared by adding a small amount of nanoparticles with one dimension smaller than $100 \mathrm{~nm}$ into base salts. It was first studied by Shin and Banerjee ${ }^{15}$ in 2011. They proposed three independent competing inter-molecular interaction mechanisms. One of them suggested that the interfacial thermal resistance between the nanoparticles and base liquids provided extra thermal storage capability. Since then, numerous studies have been conducted. ${ }^{16}$ It was reported that enhancements of specific heat, thermal conductivity and energy storage capacity were observed in molten nitrate salts due to the addition of $\mathrm{CuO},{ }^{17-19} \mathrm{Al}_{2} \mathrm{O}_{3}{ }^{20}$ and $\mathrm{SiO}_{2}{ }^{21-24}$ nanoparticles. Luo et al. ${ }^{17}$ synthesized composite nitrate salts composed of binary salt ( 60 wt. $\% \mathrm{NaNO}_{3}-40$ wt.\% $\mathrm{KNO}_{3}$ ) and $\mathrm{CuO}$ nanoparticles $(\sim 20 \mathrm{~nm})$. The maximum enhancements of specific heat and total storage capacity were $11.48 \%$ for the liquid phase and $4.71 \%$ over the base salt, respectively. Jr et al. ${ }^{18}$ focused on three nitrate salts: $\mathrm{KNO}_{3}$, 
$\mathrm{NaNO}_{3}$ and $\mathrm{KNO}_{3}-\mathrm{NaNO}_{3}(51.8: 48.2$ mole\%) with $\mathrm{CuO}$ as nanoparticles $(\sim 40 \mathrm{~nm})$. The improvements in thermal conductivity were observed for all the measurements. $\mathrm{Hu}$ et al $^{20}$ investigated the effect of doping eutectic binary salt $\left(\mathrm{NaNO}_{3}-\mathrm{KNO}_{3}\right)$ with $\mathrm{Al}_{2} \mathrm{O}_{3}$ nanoparticles $(20 \mathrm{~nm})$ on its specific heat capacity. Results showed that the enhancement of the specific heat capacity ranged from $1.9 \%$ to $8.3 \%$ with the mass fraction of nanoparticles varying from $0.5 \%$ to $2 \%$. Seo and $\mathrm{Shin}^{21}$ doped different sizes of $\mathrm{SiO}_{2}$ nanoparticles $(5-60 \mathrm{~nm})$ into ternary nitrate salt eutectic $\mathrm{LiNO}_{3}-\mathrm{NaNO}_{3}-\mathrm{KNO}_{3}(38: 15: 47 \mathrm{~mole} \%)$ at a $1 \%$ mass fraction. The specific heat of the mixture was enhanced by $13-16 \%$ and nanoparticle size had little effect on the specific heat. Chen et al. ${ }^{23}$ studied molten salt based nanofluids which possessed lowmelting point salt $\mathrm{Ca}\left(\mathrm{NO}_{3}\right)_{2} \cdot 4 \mathrm{H}_{2} \mathrm{O}-\mathrm{KNO}_{3}-\mathrm{NaNO}_{3}-\mathrm{LiNO}_{3}$ (2:6:1:2 wt.\%) as base liquid and $\mathrm{SiO}_{2}$ as nanoparticles with a diameter of $20 \mathrm{~nm}$. The specific heat was improved by $24.5 \%$ at a mass fraction of $0.5 \%$. The mechanism of the enhancements was also disclosed. It was reported that the solid-like nanolayer around the surface of the nanoparticles ${ }^{25-27}$ and fractal-like fluid nanostructures ${ }^{27-29}$ contributed to the enhancement of specific heat capacity and thermal conductivity.

On the other hand, some research showed that sometimes the addition of nanoparticles resulted in unfavourable properties of molten nitrate salts. ${ }^{30-33}$ Chieruzzi et al..$^{30}$ dispersed $\mathrm{SiO}_{2}(7 \mathrm{~nm}), \mathrm{Al}_{2} \mathrm{O}_{3}(13 \mathrm{~nm})$ and a mix of $\mathrm{SiO}_{2} / \mathrm{Al}_{2} \mathrm{O}_{3}(2-200 \mathrm{~nm})$ nanoparticles into $\mathrm{NaNO}_{3}-\mathrm{KNO}_{3}$ solar salt $(60-40 \mathrm{wt} \%)$ at $300{ }^{\circ} \mathrm{C}$, respectively. The results showed that significant enhancement of the specific heat capacity only occurred for the solar salt with $\mathrm{SiO}_{2} / \mathrm{Al}_{2} \mathrm{O}_{3}$ nanoparticles. Nanofluids consisting of $\mathrm{NaNO}_{3}-\mathrm{KNO}_{3}$ (60-40 wt.\%) and Al-Cu nanoparticles (80-20 wt.\%, 20$300 \mathrm{~nm}$ ) were prepared by Navarrete et $a l^{31}$ The specific heat was decreased by up to $10 \%$ at all mass fractions of nanoparticles. What's more, the thermal conductivity was decreased by $\sim 24 \%$ at the $10 \mathrm{wt} . \%$ nanoparticles. Awad et al. ${ }^{32}$ used a binary nitrate salt $\mathrm{NaNO}_{3}-\mathrm{KNO}_{3}(60-$ $40 \mathrm{~mole} \%)$ as the base salts dispersed with $\mathrm{Fe}_{2} \mathrm{O}_{3}(20-40 \mathrm{~nm}), \mathrm{TiO}_{2}(\sim 50$ $\mathrm{nm})$ and $\mathrm{CuO}(<50 \mathrm{~nm})$ nanoparticles, respectively. The $\mathrm{Fe}_{2} \mathrm{O}_{3}$ and $\mathrm{CuO}$ nanoparticles showed positive effect on the properties of nitrate salts. However, the $\mathrm{TiO}_{2}$ nanoparticles decreased the specific heat of liquid phase and total energy storage capacity by $14.6 \%$ and $12 \%$, respectively. Grosu et al. ${ }^{33}$ tested the corrosivity of Hitec XL salt (15 wt. $\% \mathrm{NaNO}_{3}, 43$ wt. $\% \mathrm{KNO}_{3}$ and 42 wt. $\% \mathrm{Ca}\left(\mathrm{NO}_{3}\right)_{2}$ ) doped with two different nanoparticles $\mathrm{Al}_{2} \mathrm{O}_{3}(13 \mathrm{~nm})$ and $\mathrm{SiO}_{2}(12 \mathrm{~nm})$. It was found that the corrosion rate of carbon steel was increased by 2-3 times due do the fact that the nanoparticles entrapped additional air in the inter particle pores which accelerated the corrosion.

As shown above, it is quite controversial regarding the effect of adding nanoparticles into molten nitrate salts, and there is not a wellacknowledged model or theory that explains the anomalous behaviour of molten salt based nanofluids. Therefore, more experimental and theoretical studies are needed considering various parameters, such as different base salts, nanoparticle types, nanoparticle sizes, nanoparticle concentration, material temperatures, material preparation methods, etc. In this paper, three molten nitrate salts based nanofluids are prepared with single nitrate salts $\mathrm{LiNO}_{3}, \mathrm{NaNO}_{3}$ and $\mathrm{KNO}_{3}$ as the base salts and $\mathrm{SiO}_{2}$ as the nanoparticles. Experimental studies are conducted considering different nanoparticle sizes $(15 \mathrm{~nm}-5 \mu \mathrm{m})$, mass fractions $(0.5-4 \%)$ and temperatures $\left(200-380{ }^{\circ} \mathrm{C}\right)$. The effects of nanoparticles on thermo-physical properties of the molten nitrate salts are disclosed, including material structure, melting point, latent heat, specific heat capacity and thermal conductivity. This experimental study will provide valuable data for the development of theoretical models.

\section{Experiment procedures}

\subsection{Materials selection}

Inorganic salts are used in this study for high temperature thermal energy storage applications. These salts are among the most favourable candidates due to their virtues of thermophysical properties and stability. Rather than using eutectic salt mixtures, single salt is chosen with the aim of simplifying the system and eliminating interference factors that may affect the observation of the underlying physics. The salts used in the experiment are $\mathrm{LiNO}_{3}, \mathrm{NaNO}_{3}$ and $\mathrm{KNO}_{3}$ with the purity of $99.0 \%$, purchased from Sigma-Aldrich.

$\mathrm{SiO}_{2}$ is chosen as the nanoparticles to enhance the thermal physical properties of the salts. $\mathrm{SiO}_{2}$ nanoparticles with different average particle sizes $(15-20 \mathrm{~nm}, 20-30 \mathrm{~nm}, 60-70 \mathrm{~nm}, 1-5 \mu \mathrm{m})$ are used to investigate the mechanisms of the enhancement. Those particles are purchased from US Research Nanomaterials with the purity of $99.5 \%$. The density of pure materials is shown in Table 1, and the density of composite materials is calculated based on mixing rules.

\subsection{Sample preparation}

Fig. 1 illustrates the process of sample preparation for the salts with nanoparticles well dispersed. Salt and nanoparticles are weighed first with an analytical balance with $\pm 0.1 \mu \mathrm{g}$ precision (Mettler Toledo, type $\mathrm{XP6U})$. The nanoparticles are then dispersed in distilled water (typically

Table 1 Density of materials at room temperature.

\begin{tabular}{cc}
\hline Material & Density $\left(\mathrm{g} \mathrm{cm}^{-3}\right)$ \\
\hline $\mathrm{NaNO}_{3}$ (Sigma-Aldrich) & 2.26 \\
$\mathrm{LiNO}_{3}$ (Sigma-Aldrich $)$ & 2.38 \\
$\mathrm{KNO}_{3}$ (Sigma-Aldrich) & 2.11 \\
$\mathrm{SiO}_{2}(\mathrm{US}$ research nanomaterial $)$ & 2.40 \\
\hline
\end{tabular}

Distilled water

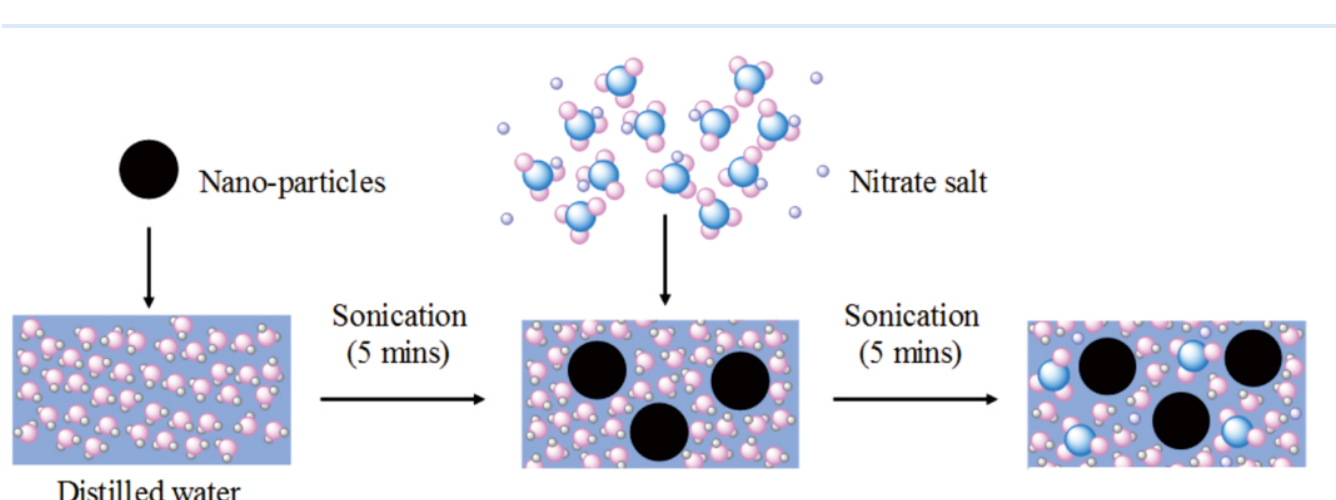

Fig. 1 Ultrasonic mixing method for making salt-based nanomaterials.

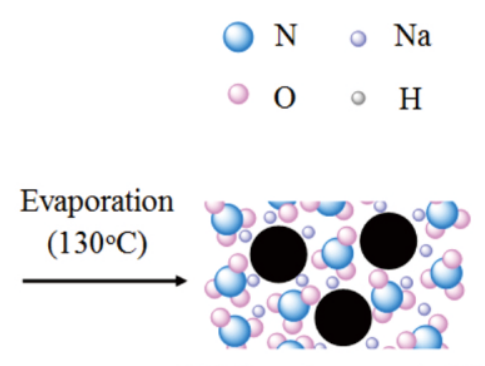

Salt-based nanomaterial 
$20 \mathrm{ml}$ ) in a beaker and mixed by a high power ultrasonicator (Fisher scientific, CL 334) for 5 minutes. The salts are then added to the aqueous based suspensions, and the resulting mixture is subjected to sonication for a further 5 minutes. The beaker is subsequently placed on a hot plate set at $130{ }^{\circ} \mathrm{C}$ to evaporate the water. This process gives a well dispersed salt-particle mixture. This method is similar to that used by Shin and Banerjee. ${ }^{15}$ However, instead of employing an ultrasonic bath and mixing the sample for 2 and 3 hours, a $500 \mathrm{~W}$ ultrasonicatoris used in this work and the mixing time is 5 minutes. This is because, after subjecting the aqueous suspension to the sonication for 5 minutes, the size of nanoparticles shows little change with longer sonicationas indicated by the results of the Zetasizer. In this work, salts with different mass fractions of nanoparticles $(0.5 \%, 1.0 \%, 2.0 \%$, and $4.0 \%)$ are prepared. Pure salts without nanoparticles are also prepared using the method to serve as the benchmark sample for results comparison. In addition, each test is made three times to ensure repeatability and minimize experimental errors. After each measurement, we cleaned the crucible with an ultra-sonic bath to ensure there is no contamination left in the crucible after each test. The procedure is as follows: we immerse crucible in a beaker of distilled water. We employed an ultra-sonic bath to clean the crucible in the beaker for $30 \mathrm{~min}$ and replace the water inside the beaker. After repeating the procedure twice, the crucible was placed in a drying oven at $120^{\circ} \mathrm{C}$.

\subsection{Characterization}

After the samples are prepared, their thermo-physical properties are tested, including decomposing temperature, crystal structure, melting point, latent heat capacity, specific heat capacity and thermal conductivity. The testing instruments are shown in Table 2.

Differential Scanning Calorimetry (DSC) is used to measure the melting point, latent heat capacity and the specific heat capacity. When the sample is undergoing a phase transition, more heat will flow to the sample than that to the reference to maintain both at the same temperature. By detecting this heat flow difference, the device will be able to work out the amount of heat absorbed or released during the phase change and hence the latent heat of the phase change by integrating the heat flow difference with respect to time. The onset of the heat flow variation is defined as the melting point. The specific heat capacity is measured with the ASTM E1269-05 standard. A synthetic sapphire disk ( $\alpha$-aluminium oxide; alumina) was used as a heat flow calibration standard. The specific heat capacity of a sample is calculated by the following formula:

$$
C_{p(\text { sample) }}=C_{p(\text { standard })} \cdot \frac{H F_{(\text {sample) }} \cdot m_{\text {(standard) }}}{H F_{(\text {standard })} \cdot m_{\text {(sample) }}}
$$

where $C_{p(s a m p l e)}$ and $C_{p(s t a n d a r d)}$ are specific heat capacities of the sample and sapphire standard, respectively; $H F_{(\text {sample) }}$ and $H F_{\text {(standart) }}$ are corrected heat flows of the sample and standard sapphire, respectively; $m_{\text {(sample) }}$ and $m_{\text {(standard) }}$ are mass of the sample and standard sapphire, respectively.

Laser flash analysis (LFA) is employed to measure the thermal diffusivity and thermal conductivity of the samples. A laser pulse is used to momentarily heat the bottom side of a sample with $12.5-14 \mathrm{~mm}$ diameter and 0.5-4 mm thickness. The temperature of the sample on the top side is measured with a radiation thermometer as a function of time. The thermal diffusivity can then be calculated by:

$$
\alpha=0.1388 \cdot l^{2} / t_{\frac{1}{2}}
$$

where $l$ is the thickness of the sample; $t_{\frac{1}{2}}$ is the time difference between the initiation of the pulse and the top side temperature when it reaches one-half of the maximum value. The thermal conductivity then can be related to the thermal diffusivity by:

$$
\lambda=\alpha C_{p} \rho
$$

where $\lambda$ is the thermal conductivity of the sample; $C_{p}$ is the specific heat capacity of the sample; $\rho$ is the density of the sample.

\subsection{Uncertainty}

The uncertainty of results comes from equipment uncertainty, propagation of uncertainty and artificial uncertainty. In our test, each property of the materials is measured three times to minimize the artificial uncertainty. Suppose independent parameters $X_{1}, X_{2}, \ldots, X_{n}$ are measured with uncertainties $\delta \mathrm{X}_{1}, \delta \mathrm{X}_{2}, \ldots, \delta \mathrm{X}_{\mathrm{n}}$, and the measured parameters are used to calculate the function $\mathrm{R}\left(\mathrm{X}_{1}, \mathrm{X}_{2}, \ldots, \mathrm{X}_{\mathrm{n}}\right)$. Then, the uncertainty of $\mathrm{R}$ is calculated with the following equation:

$$
\delta R=\sqrt{\Sigma_{n=1}^{N}\left(\frac{\partial R}{\partial}\right)\left(\delta X_{n}\right)^{2}}
$$

\section{Results and discussion}

\subsection{Decomposing temperature}

All three nitrate salts decompose at a high temperature. As is shown in Fig. 2, the salts are heated to $800{ }^{\circ} \mathrm{C}$ in the atmosphere of helium. Significant mass loss occurs in $\mathrm{LiNO}_{3}$ at $557{ }^{\circ} \mathrm{C}$, which indicates the beginning of the decomposition. Considerable mass loss of $\mathrm{NaNO}_{3}$ and $\mathrm{KNO}_{3}$ is observed at 607 and $649{ }^{\circ} \mathrm{C}$, respectively. In order to avoid the decomposition and insure the repeatability of our experiments, the temperatures in the corresponding tests in this work are set much lower than the decomposition temperature.

\subsection{Materials structure}

Table 2 Instruments to test thermo-physical properties in this work.

\begin{tabular}{lll}
\hline Name & Purpose & Manufacturer \\
\hline Differential Scanning Calorimetry (DSC) & Specific heat capacity, melting point, latent heat & Mettler Toledo \\
Simultaneous Thermal Analyzer (STA) & Thermal stability & Netzsch \\
Laser Flash Apparatus (LFA ) & Thermal conductivity & Netzsch \\
Zetasizer & Size of nanoparticles & Malvern \\
X-ray diffraction (XRD) & Crystal structure & Siemens \\
\hline
\end{tabular}


The structural analysis is performed on the pure salts and their nanoparticle mixtures using an X-Ray Diffractometer. Before the analysis, the pure salts and nanoparticle mixtures are cycled 50 times $\left(200-350{ }^{\circ} \mathrm{C}\right.$ for $\mathrm{NaNO}_{3}, 200-310{ }^{\circ} \mathrm{C}$ for $\mathrm{LiNO}_{3}$ and $270-380{ }^{\circ} \mathrm{C}$ for $\mathrm{KNO}_{3}$ ) at a heating/cooling rate of $10{ }^{\circ} \mathrm{C} / \mathrm{min}$ for stabilizing the physical structure. Fig. 3 shows the XRD graphs of the pure salts and their mixtures with $0.5 \%, 15-20 \mathrm{~nm} \mathrm{SiO}_{2}$. One can see that the addition of the nanoparticles does not change crystallinity of the nitrate salts and there is no new phase created. The $\mathrm{SiO}_{2}$ particles used are amorphous and hence are reflected in the XRD graphs.

\subsection{Melting point and latent heat}

The melting point and latent heat of the pure salts $\left(\mathrm{NaNO}_{3}, \mathrm{KNO}_{3}\right.$ and $\mathrm{LiNO}_{3}$ ) are shown in Fig. 4.

One can see that the pure $\mathrm{NaNO}_{3}$ has a melting point of $305.9{ }^{\circ} \mathrm{C}$ and latent heat of $\sim 179 \mathrm{~kJ} / \mathrm{kg}$. The pure $\mathrm{LiNO}_{3}$ salt has a melting point of $255.2{ }^{\circ} \mathrm{C}$ and latent heat of $370.6 \mathrm{~kJ} / \mathrm{kg}$. The pure $\mathrm{KNO}_{3}$ has a melting point of $333.9{ }^{\circ} \mathrm{C}$ and latent heat of $99.2 \mathrm{~kJ} / \mathrm{kg}$.

Fig. 5 shows how the addition of $\mathrm{SiO}_{2}$ nanoparticles affects the melting point of the pure salts $\left(\mathrm{NaNO}_{3}, \mathrm{KNO}_{3}\right.$ and $\left.\mathrm{LiNO}_{3}\right)$. As shown in

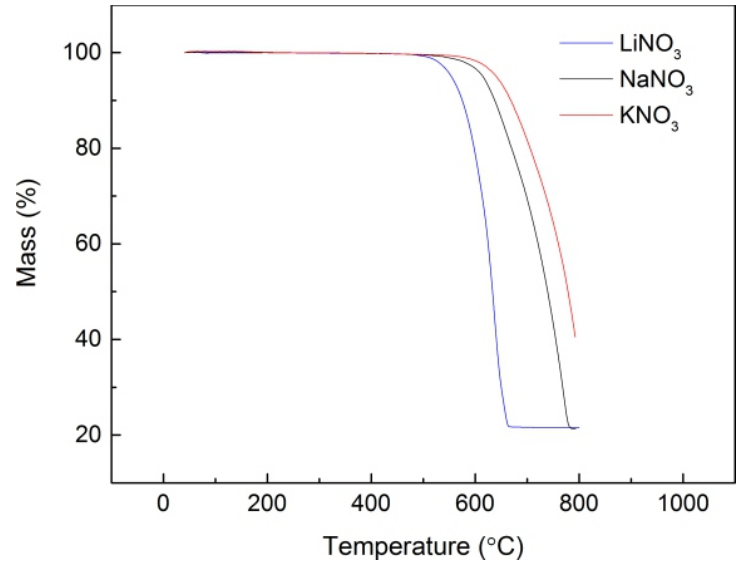

Fig. 2 Thermogravimetric analysis of three nitrate salts.

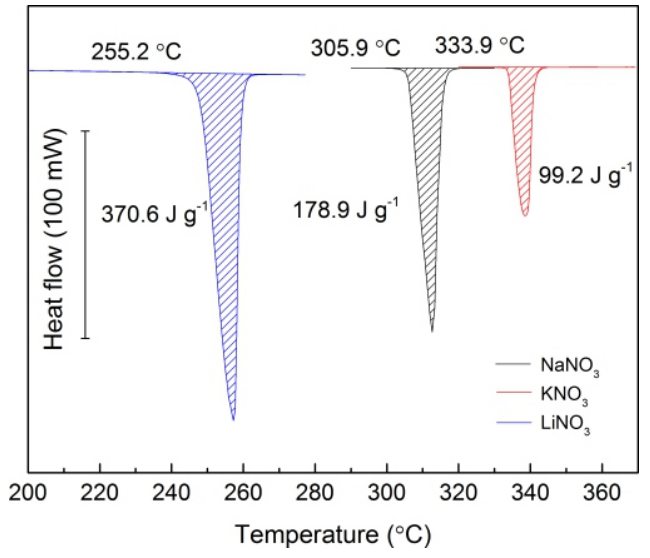

Fig. 4 Melting point and latent heat of pure $\mathrm{NaNO}_{3}, \mathrm{LiNO}_{3}$ and $\mathrm{KNO}_{3}$.

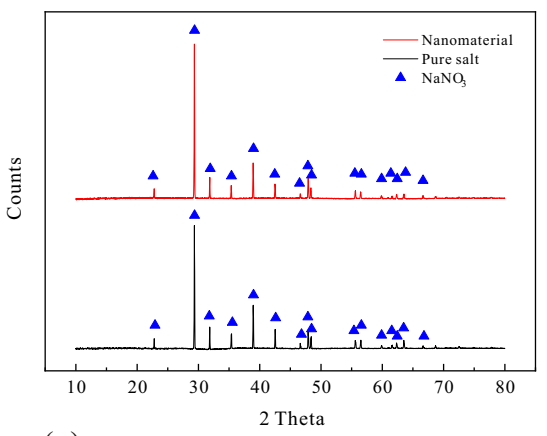

(a)

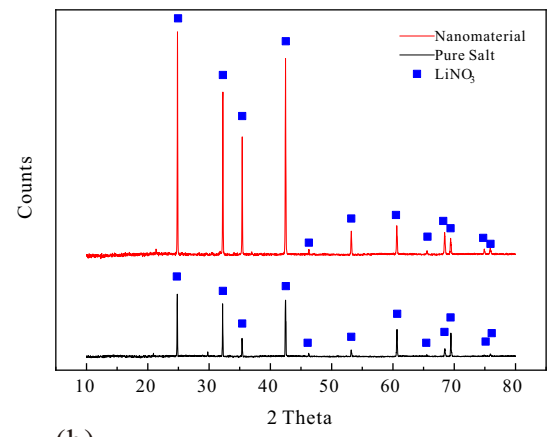

(b)

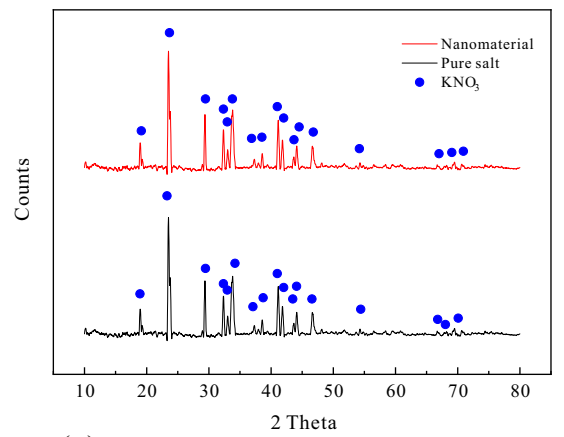

(c)

Fig. 3 XRD analysis of (a) $\mathrm{NaNO}_{3}$, (b) $\mathrm{LiNO}_{3}$ and (c) $\mathrm{KNO}_{3}$ with $0.5 \%, 15-20 \mathrm{~nm} \mathrm{SiO}$, nanoparticles.
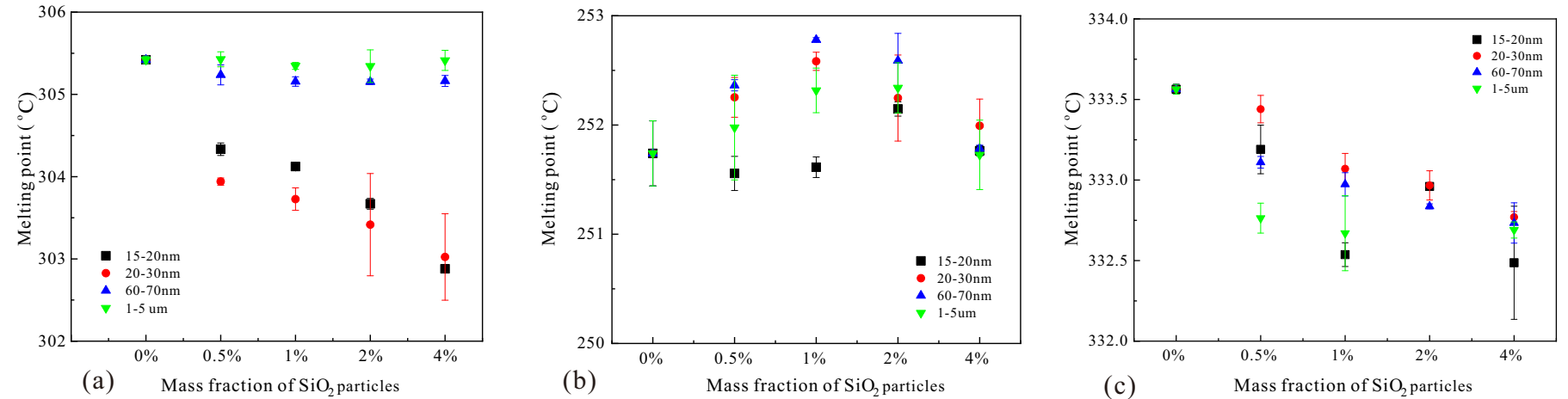

Fig. 5 Melting point of (a) $\mathrm{NaNO}_{3}$, (b) $\mathrm{LiNO}_{3}$ and (c) $\mathrm{KNO}_{3}$ with $\mathrm{SiO}_{2}$ nanoparticles. 
Fig. 5(a), the addition of smaller nanoparticles (15-20 $\mathrm{nm}$ and 20-30 $\mathrm{nm}$ ) appears to give a decrease in the melting point of $\mathrm{NaNO}_{3}$, which leads to up to $\sim 2.5{ }^{\circ} \mathrm{C}$ in the melting point with $4 \% \mathrm{SiO}_{2}$ nanoparticles. However, particles with larger diameters $(60-70 \mathrm{~nm}$ and 1-5 $\mu \mathrm{m})$ do not cause a significant impact on the melting point. As known, the melting point of a solution falls along with the mass fraction of the solute. The quantitative dependency is related to the variation of the system free energy after adding the solute. The nanoparticles are small, which is analogous to the solute in the molten salt. The smaller nanoparticles have considerable specific surface area and act as nucleation sites, which decreases the free energy required for phase change and hence decreases the melting point. The measured melting point for $\mathrm{LiNO}_{3}$ with $\mathrm{SiO}_{2}$ nanoparticlesis shown in Fig. 5(b). The addition of all sizes of $\mathrm{SiO}_{2}$ nanoparticles gives a change of the melting point within $\sim 1{ }^{\circ} \mathrm{C}$ and mass fraction of $\mathrm{SiO}_{2}$ nanoparticles does not seem to have a much effect. The impact of the introduction of $\mathrm{SiO}_{2}$ nanoparticles on the melting point of $\mathrm{KNO}_{3}$ is shown in Fig. 5(c). Overall, the addition of $\mathrm{SiO}_{2}$ nanoparticles to the salt decreases the melting point, and the extent of decrease appears to increase with nanoparticle concentration. This is similar to the results shown in Fig. 5(a) for $\mathrm{NaNO}_{3}$ salt. However, the decrease in the melting point is small, within $\sim 1{ }^{\circ} \mathrm{C}$, and hence is insignificant.

The latent heat of $\mathrm{NaNO}_{3}$ with $\mathrm{SiO}_{2}$ nanoparticles is shown in Fig. 6. By adding 15-20 and 20-30 nm nanoparticles, the latent heat shows a decreasing trend with the increasing mass fraction of $\mathrm{SiO}_{2}$ nanoparticles, as shown in Fig. 6(a) and (b), respectively. The $\mathrm{NaNO}_{3}$ with $\mathrm{SiO}_{2}$ nanoparticles exhibit a lower latent heat than the pure salt. As the mass fraction of $\mathrm{SiO}_{2}$ nanoparticles is $4 \%$, the latent heat of $\mathrm{NaNO}_{3}$ with 15 20 and $20-30 \mathrm{~nm}$ nanoparticles is 167.2 and $162.1 \mathrm{~kJ} / \mathrm{kg}$, respectively. For the $60-70 \mathrm{~nm} \mathrm{SiO}_{2}$ nanoparticles, as shown in Fig. 6(c), little changes are seen on the latent heat due to the introduction of $0.5 \%, 1 \%$ and $2 \% \mathrm{SiO}_{2}$ nanoparticles. However, the latent heat decreases to 166.7 $\mathrm{kJ} / \mathrm{kg}$ by introducing $4 \% \mathrm{SiO}_{2}$ nanoparticles. The addition of $1-5 \mu \mathrm{m}$ $\mathrm{SiO}_{2}$ particles does not show any significant impact on the latent heat, as shown in Fig. 6(d).

The latent heat of $\mathrm{LiNO}_{3}$ with $\mathrm{SiO}_{2}$ nanoparticles is shown in Fig. 7. The addition of $15-20 \mathrm{~nm} \mathrm{SiO}_{2}$ nanoparticles decreases the latent heat of $\mathrm{LiNO}_{3}$, and the extent of the decrease depends on the mass fraction of $\mathrm{SiO}_{2}$ nanoparticles, as shown in Fig. 7(a). With 0.5\% nanoparticles, the latent heat decreases to $368.8 \mathrm{~kJ} / \mathrm{kg}$, and it decreases to $351.6 \mathrm{~kJ} / \mathrm{kg}$ with $4 \%$ nanoparticles. For the $20-30 \mathrm{~nm} \mathrm{SiO}_{2}$ nanoparticles, as shown in Fig. 7(b), the addition of $0.5 \%$ or $1 \%$ nanoparticles increases the latent heat, whereas further increasing the nanoparticles to $2 \%$ and $4 \%$ shows a decrease in the latent heat, compared with the pure salt. The largest latent heat of $\sim 377 \mathrm{~kJ} / \mathrm{kg}$ is obtained as the mass fraction of $\mathrm{SiO}_{2}$ nanoparticles is $1 \%$. Fig. 7 (c) shows similar observations for the $60-70$ $\mathrm{nm} \mathrm{SiO}_{2}$ nanoparticles. With the mass fraction of $\mathrm{SiO}_{2}$ nanoparticles increasing from $0.5 \%$ to $1 \%$, the latent heat increases gradually, while it increases from $1 \%$ to $4 \%$, the latent heat decreases significantly. The largest latent heat of $\sim 378 \mathrm{~kJ} / \mathrm{kg}$ is achieved as the mass fraction of $\mathrm{SiO}_{2}$ nanoparticles is $1 \%$. As shown in Fig. 7(d), for $1-5 \mu \mathrm{m} \mathrm{SiO}_{2}$ nanoparticles, the addition of $0.5 \%, 1 \%$ and $2 \% \mathrm{SiO}_{2}$ nanoparticles
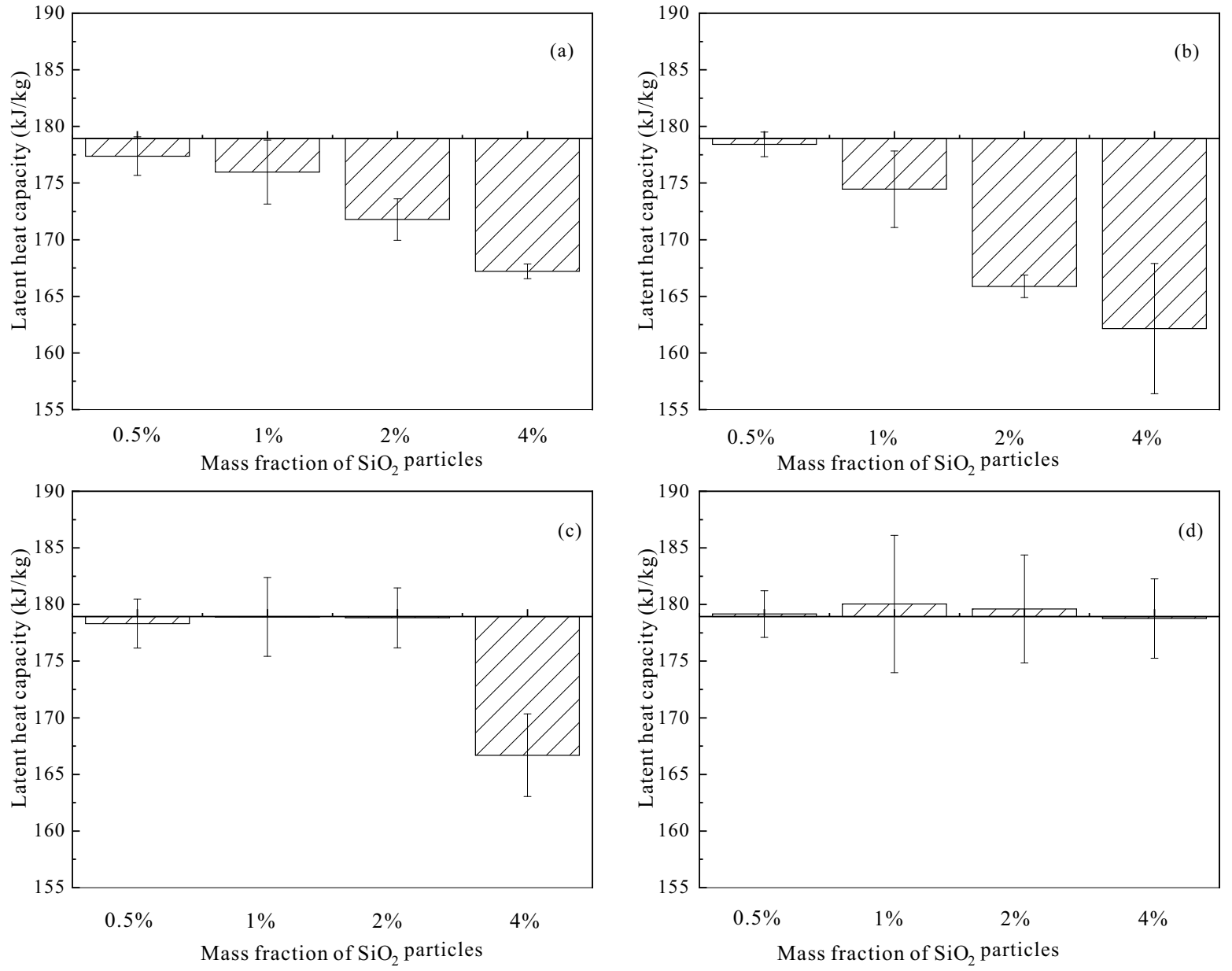

Fig. 6 Latent heat capacity of $\mathrm{NaNO}_{3}$ with various $\mathrm{SiO}_{2}$ particle sizes: (a) 15-20 nm; (b) 20-30 nm; (c) 60-70 nm; (d)1-5 $\mu$ m. 

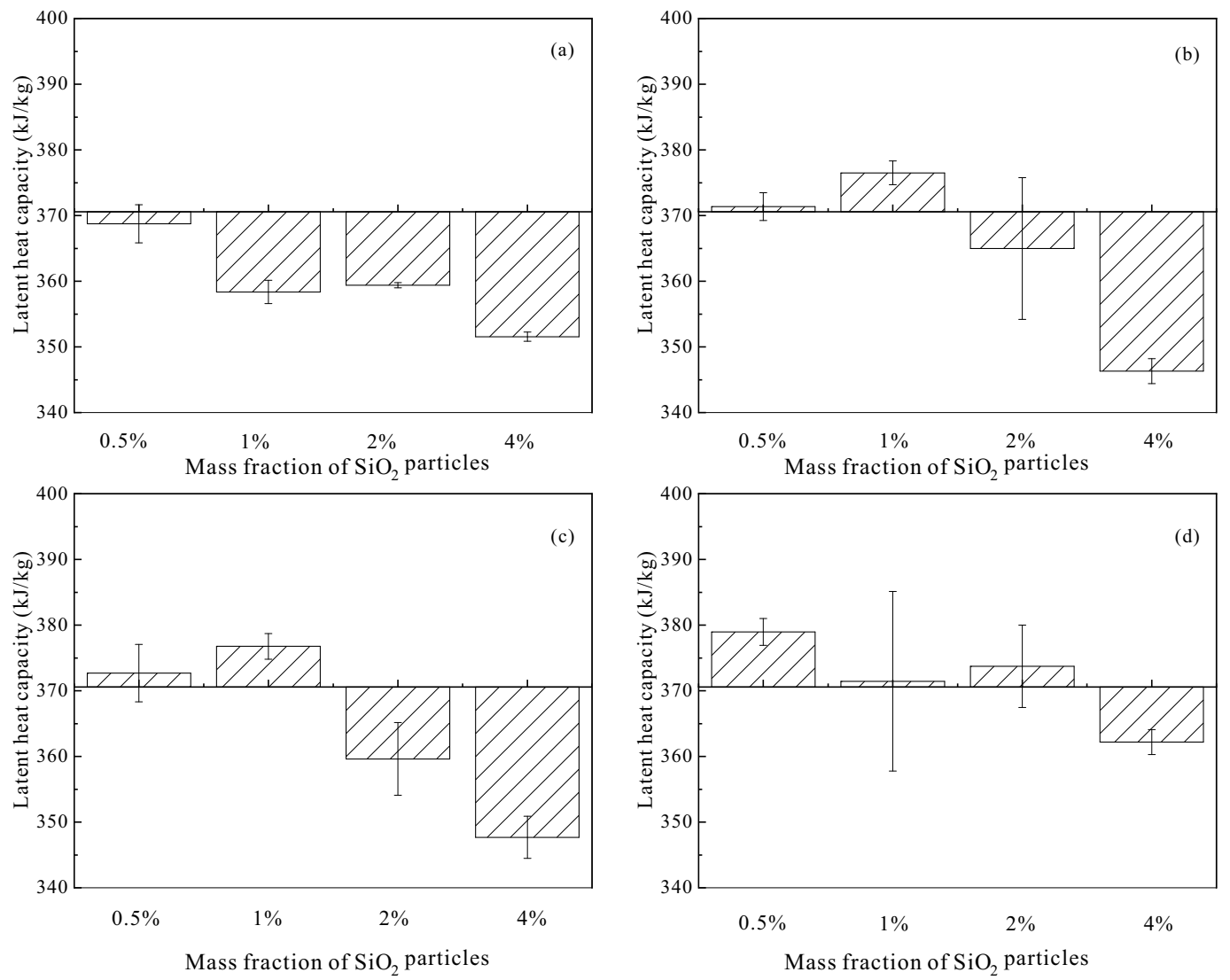

Fig. 7 Latent heat capacity of $\mathrm{LiNO}_{3}$ with various $\mathrm{SiO}_{2}$ particle sizes: (a) 15-20 nm; (b) 20-30 nm; (c) 60-70 nm; (d)1-5 $\mu$ m.
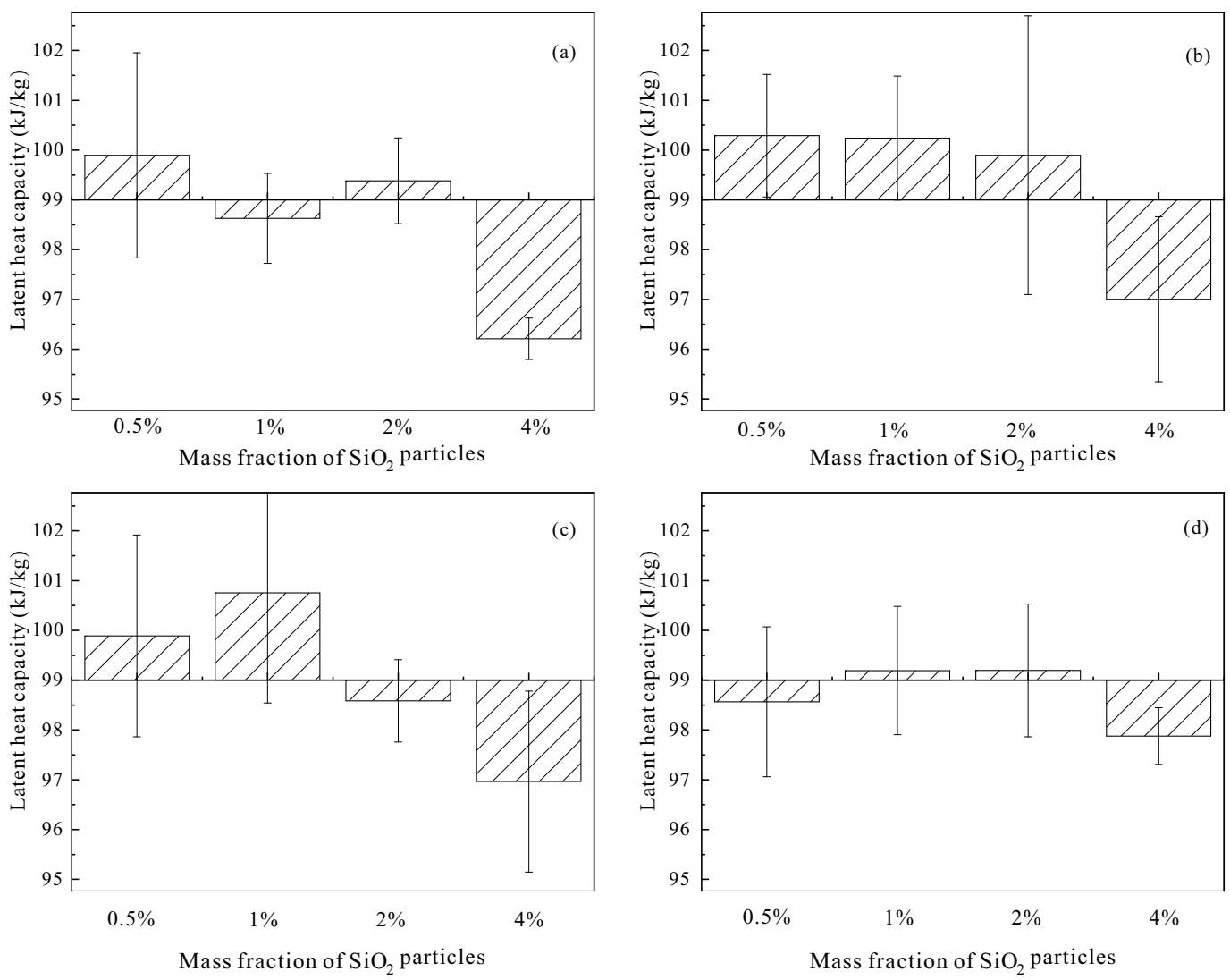

Fig. 8 Latent heat capacity of $\mathrm{KNO}_{3}$ with various $\mathrm{SiO}_{2}$ particle sizes: (a) 15-20 nm; (b) 20-30 nm; (c) 60-70 nm; (d)1-5 $\mu \mathrm{m}$. 
gives an increase in the latent heat, whereas the addition of $4 \% \mathrm{SiO}_{2}$ nanoparticles leads to a lower latent heat than the pure salt. The suggested mass fraction of $\mathrm{SiO}_{2}$ nanoparticles is $0.5 \%$ and corresponding latent heat is $\sim 379 \mathrm{~kJ} / \mathrm{kg}$.

The latent heat of $\mathrm{KNO}_{3}$ with $\mathrm{SiO}_{2}$ nanoparticles is shown in Fig. 8 . The addition of $15-20 \mathrm{~nm} \mathrm{SiO}_{2}$ nanoparticles leads to changes to the latent heat and the extent of changes depends on the mass fraction of $\mathrm{SiO}_{2}$ nanoparticles, as shown in Fig. 8(a). The largest latent heat of $\sim 99.9 \mathrm{~kJ} / \mathrm{kg}$ is achieved as the mass fraction of $\mathrm{SiO}_{2}$ nanoparticles is at $0.5 \%$. Introducing $20-30 \mathrm{~nm} \mathrm{SiO}$ nanoparticles into $\mathrm{KNO}_{3}$ gradually decreases the latent heat as the mass fraction of $\mathrm{SiO}_{2}$ nanoparticles increases from $0.5 \%$ to $4 \%$, as shown in Fig. 8(b). The largest latent heat of $\sim 100.3 \mathrm{~kJ} / \mathrm{kg}$ is obtained with $0.5 \% \mathrm{SiO}_{2}$ nanoparticles. For the 60-70 $\mathrm{nm} \mathrm{SiO}_{2}$ nanoparticles, as shown in Fig. 8(c), the latent heat increases gradually to $\sim 100.8 \mathrm{~kJ} / \mathrm{kgas}$ the mass fraction of $\mathrm{SiO}_{2}$ nanoparticles increases to $1 \%$ and then decreases generally with further increasing the mass fraction of $\mathrm{SiO}_{2}$ nanoparticles. Fig. 8(d) shows that the addition of 1-5 $\mu \mathrm{m} \mathrm{SiO}_{2}$ nanoparticles has little effect on the latent heat as the mass fraction of $\mathrm{SiO}_{2}$ nanoparticles is $1 \%$ or $2 \%$. However, with $0.5 \%$ and $4 \% \mathrm{SiO}_{2}$ nanoparticles, a lower latent heat is observed than the pure salt.

\subsection{Specific heat capacity}

Specific heat capacity is an important parameter which determines the energy storage density of sensible heat. Fig. 9 shows the specific heat capacity of $\mathrm{NaNO}_{3}$ with various $\mathrm{SiO}_{2}$ particles. For the $15-20 \mathrm{~nm} \mathrm{SiO}{ }_{2}$, enhancement of specific heat capacity occurs at all mass fraction of $\mathrm{SiO}_{2}$ nanoparticles, as shown in Fig. 9(a). The specific heat capacity increases with increasing the mass fraction of $\mathrm{SiO}_{2}$ nanoparticles and peaks at $\sim 1 \% \mathrm{SiO}_{2}$, beyond which a decrease is seen with a further increase in mass fraction of $\mathrm{SiO}_{2}$ nanoparticles. Temperature has been found to give a relatively weak effect on the enhancement of specific heat capacity. Fig. 9(b) demonstrates the specific heat capacities with 20-30 $\mathrm{nm} \mathrm{SiO}$ nanoparticles. With $0.5 \% \mathrm{SiO}_{2}$ in the salt, the specific heat capacity reaches $1.73 \mathrm{~kJ} / \mathrm{kg} / \mathrm{K}$, giving an enhancement of $6 \%$ with respect to the pure salt. A decreasing tendency occurs with further increase in the mass fraction of $\mathrm{SiO}_{2}$ nanoparticles. The peak specific heat capacity occurs at $0.5 \% \mathrm{SiO}_{2}$. The temperature appears to have

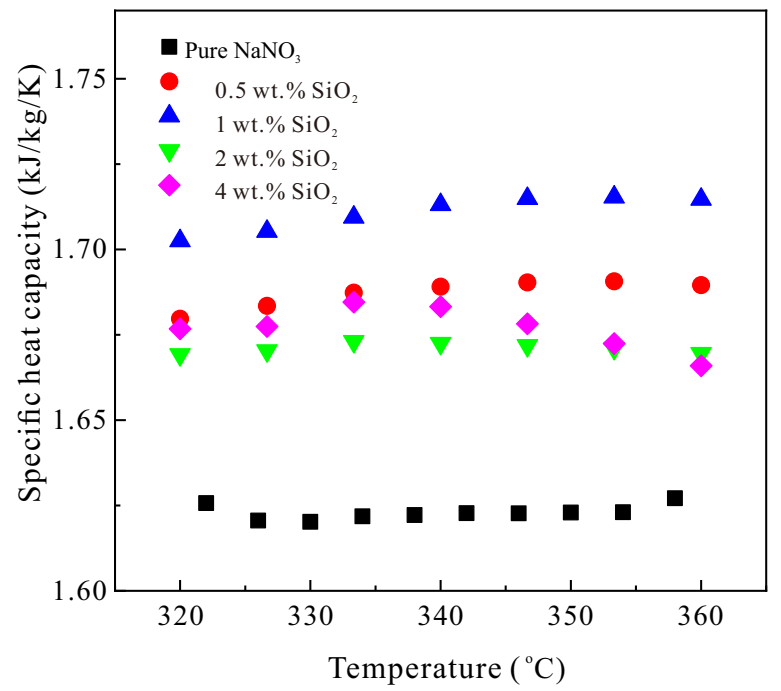

(a)

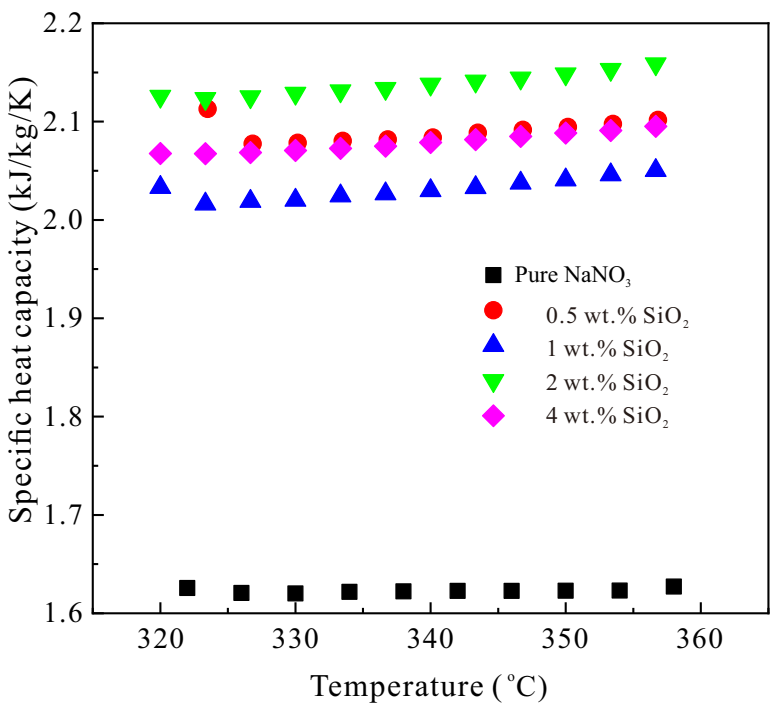

(c)

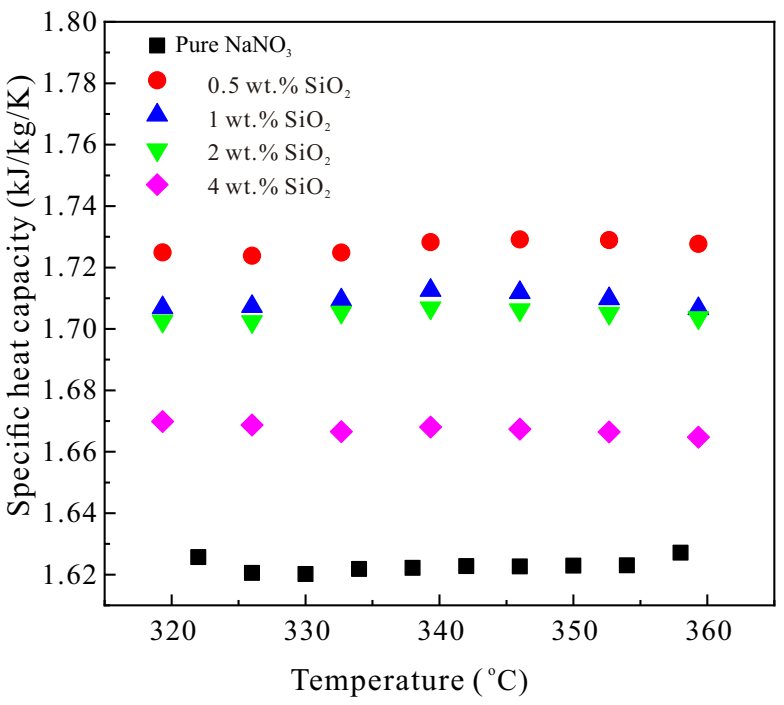

(b)

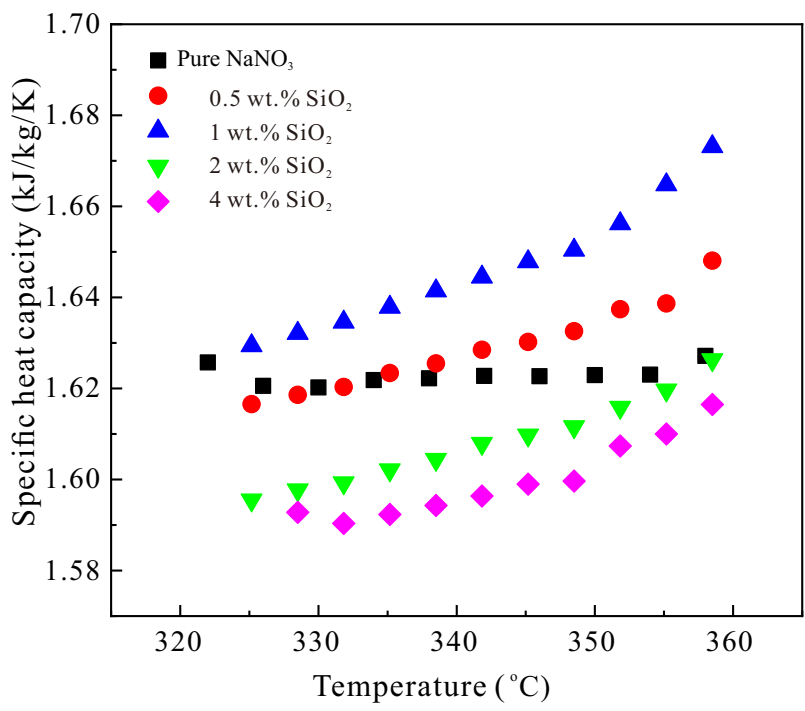

(d)

Fig. 9 Specific heat capacity of $\mathrm{NaNO}_{3}$ with various $\mathrm{SiO}_{2}$ particle sizes: (a) 15-20 nm; (b) 20-30 nm; (c) 60-70 nm; (d)1-5 $\mu \mathrm{m}$. 
little effect on the enhancement. The specific heat capacity of $\mathrm{NaNO}_{3}$ with $60-70 \mathrm{~nm} \mathrm{SiO}_{2}$ nanoparticles is shown in Fig. 9(c). A significant enhancement is observed under all mass fraction of $\mathrm{SiO}_{2}$ nanoparticles. The peak enhancement of $27.6 \%$ occurs at $2 \% \mathrm{SiO}_{2}$. In general, a higher temeprature leads to a larger specific heat capacity. The results for the 1-5 $\mu \mathrm{m} \mathrm{SiO}_{2}$ particles are shown in Fig. 9(d). One can see that the specific heat capacity is only enhanced at $0.5 \%$ and $1 \% \mathrm{SiO}_{2}$. A further increase in the mass fraction of $\mathrm{SiO}_{2}$ particles leads to a decreasing of specific heat capacity, even lower than that of the pure salt. The highest enhancement of $2.4 \%$ occurs at $1 \% \mathrm{SiO}_{2}$.

Fig. 10 shows the specific heat capacity of $\mathrm{LiNO}_{3}$ with various $\mathrm{SiO}_{2}$ particles. In terms of $15-20 \mathrm{~nm} \mathrm{SiO}_{2}$ nanoparticles, the addition of $0.5 \% \mathrm{SiO}_{2}$ gives the highest specific heat capacity of $\sim 2.10 \mathrm{~kJ} / \mathrm{kg} / \mathrm{K}$, as shown in Fig. 10(a). This is equivalent to an enhancement of $\sim 8 \%$. With an increase in the mass fraction of $\mathrm{SiO}_{2}$ nanoparticles, the specific heat capacity decreases. What's more, a higher temperature results in a larger specific heat capacity. The specific heat capacity of $\mathrm{LiNO}_{3}$ with 20-30 $\mathrm{nm} \mathrm{SiO}_{2}$ nanoparticles is shown in Fig. 10(b). A significant enhancement can be observed for $0.5 \%, 1 \%$ and $2 \% \mathrm{SiO}_{2}$ nanoparticles, with the maximum of $\sim 10.3 \%$. The highest specific heat capacity is $\sim 2.14$ $\mathrm{kJ} / \mathrm{kg} / \mathrm{K}$ at $0.5 \% \quad \mathrm{SiO}_{2}$ nanoparticles. For the 60-70 $\mathrm{nm} \mathrm{SiO}_{2}$ nanoparticles, an addition of $0.5 \% \mathrm{SiO}_{2}$ gives the maximum enhancement of specific heat capacity by $12.3 \%$, as shown in Fig. 10(c). A further increase in the mass fraction of $\mathrm{SiO}_{2}$ nanoparticles leads to the decrease of the specific heat capacity. At $4 \% \mathrm{SiO}_{2}$, it is even slightly lower than that of the pure salt. Fig. 10(d) presents that the addition of 1-5 $\mu \mathrm{m} \mathrm{SiO}_{2}$ particles only gives an enhancement when the mass fraction of $\mathrm{SiO}_{2}$ particles is at $0.5 \%$, whereas the additon of $1-4 \%$ $\mathrm{SiO}_{2}$ particles shows no or even negative enhancement.

Fig. 11 shows the specific heat capacity of $\mathrm{KNO}_{3}$ with various $\mathrm{SiO}_{2}$ particles. The specific heat capacity of $\mathrm{KNO}_{3}$ pure salt is $\sim 1.31$ $\mathrm{kJ} / \mathrm{kg} / \mathrm{K}$. With the addition of $15-20 \mathrm{~nm} \mathrm{SiO}_{2}$ nanoparticles, the maximum specific heat capacity of $\sim 1.65 \mathrm{~kJ} / \mathrm{kg} / \mathrm{K}$ is achieved as the mass fraction of $\mathrm{SiO}_{2}$ nanoparticles is at $1 \%$, and the corresponding enhancement is $\sim 26 \%$, as shown in Fig. 11(a). The increase of salt temperature leads to a slight increase of the specific heat capacity for $1 \%$ and $2 \% \mathrm{SiO}_{2}$ nanoparticles and a decrease for $0.5 \%$ and $4 \% \mathrm{SiO}_{2}$ nanoparticles. The specific heat capacity of $\mathrm{KNO}_{3}$ with $20-30 \mathrm{~nm} \mathrm{SiO}$

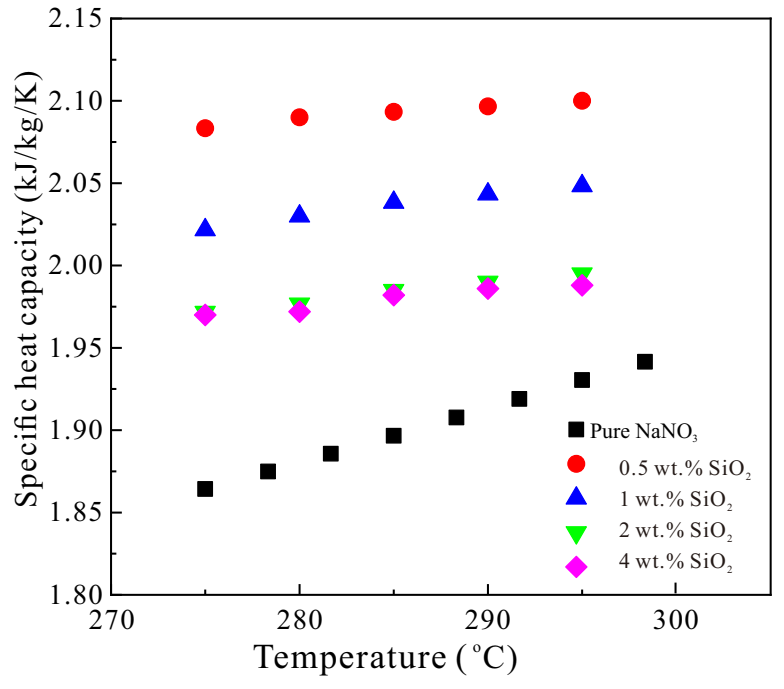

(a)

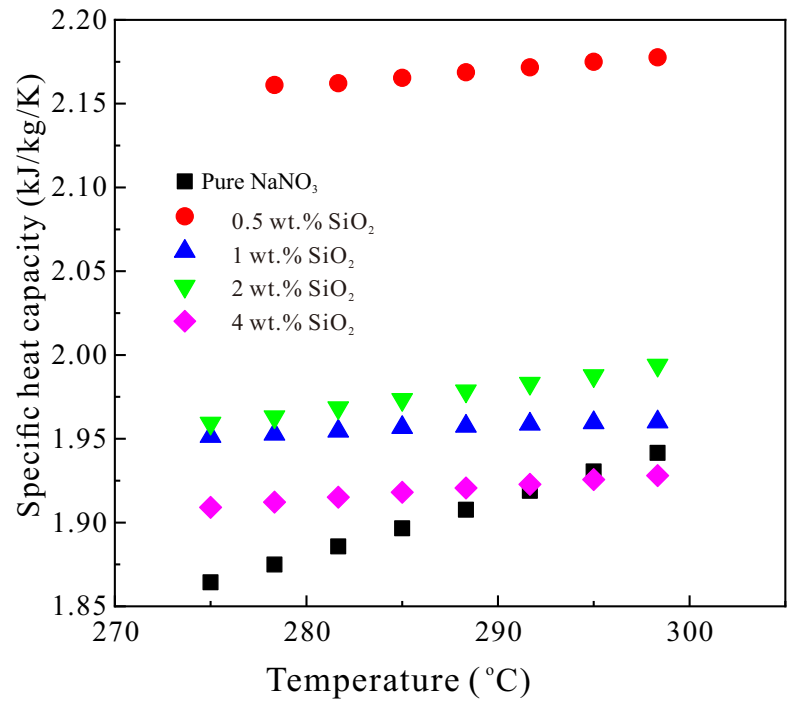

(c)

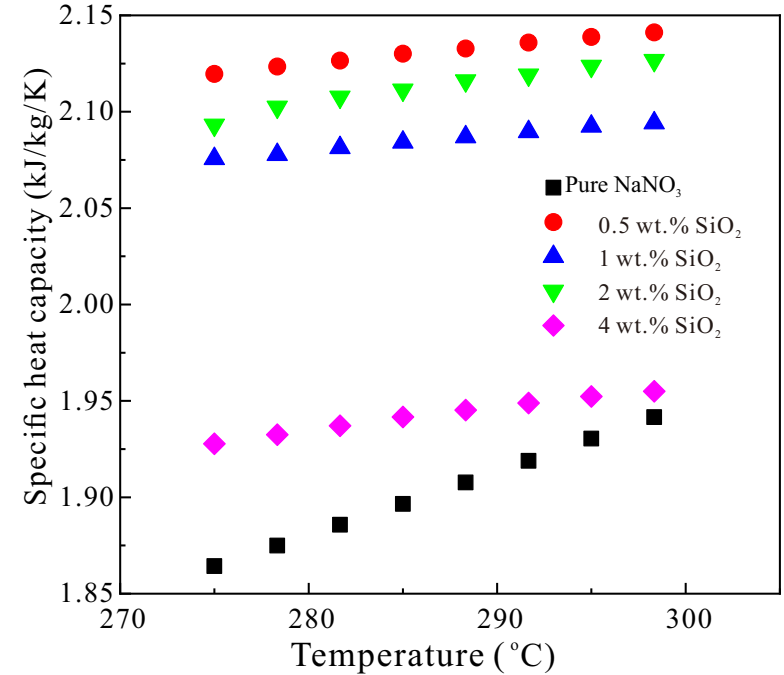

(b)

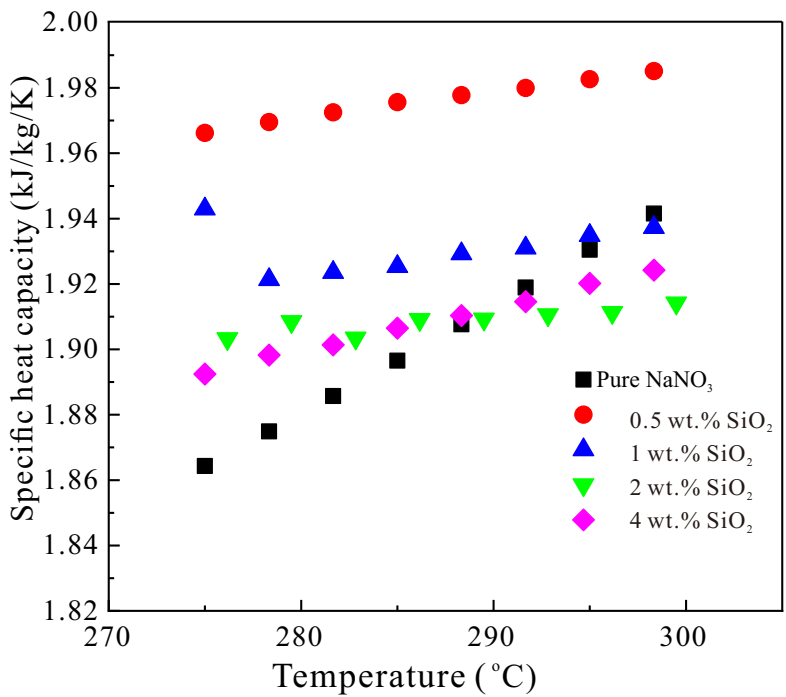

(d)

Fig. 10 Specific heat capacity of $\mathrm{LiNO}_{3}$ with various $\mathrm{SiO}_{2}$ particle sizes: (a) 15-20 nm; (b) 20-30 nm; (c) 60-70 nm; (d) 1-5 $\mu \mathrm{m}$. 
nanoparticles is presented in Fig. 11(b). The maximum specific heat capacity is obtained at $2 \% \mathrm{SiO}_{2}$ nanoparticles with the enhancement of $\sim 6.8 \%$. A higher temperature results in a larger specific heat capacity. For the addition of 60-70 $\mathrm{nm} \mathrm{SiO}_{2}$ nanoparticles, as shown in Fig. 11(c), the maximum specific heat capacity is $1.54 \mathrm{~kJ} / \mathrm{kg} / \mathrm{K}$ with mass fraction of $\mathrm{SiO}_{2}$ nanoparticles at $1 \%$; a further increase of the mass fraction leads to a decrease in the specific heat capacity. What's more, the specifc heat capacity slightly increases with the increase of salt temperature. In terms of $\mathrm{KNO}_{3}$ containing 1-5 $\mu \mathrm{m} \mathrm{SiO}_{2}$ particles, the specific heat capacity is only slightly enhanced as the mass fraction of $\mathrm{SiO}_{2}$ particles is above $2 \%$, as shown in Fig. 11(d). What's more, a slight increasing trend of the specific heat capacity is seen with the increase of salt temperature.

\subsection{Thermal conductivity}

Thermal conductivity is a key parameter to evaluate heat transfer performance. Fig. 12 shows the thermal conductivity of $\mathrm{NaNO}_{3}, \mathrm{LiNO}_{3}$, and $\mathrm{KNO}_{3}$ after melting, with the addition of $15-20 \mathrm{~nm} \mathrm{SiO}_{2}$ nanoparticles. As shown in Fig. 12(a), the pure $\mathrm{NaNO}_{3}$ has a thermal conductivity of $\sim 0.54 \mathrm{~W} / \mathrm{m} / \mathrm{K}$ in the temperature range of $320-370{ }^{\circ} \mathrm{C}$. With the introduction of $0.5 \% \mathrm{SiO}_{2}$ nanoparticles, the average thermal conductivity decreases to $0.49 \mathrm{~W} / \mathrm{m} / \mathrm{K}$. As the mass fraction of $\mathrm{SiO}_{2}$ nanoparticles increases from $0.5 \%$ to $4 \%$, the thermal conductivity decreases first and increases later. In general, the addition of $\mathrm{SiO}_{2}$ nanoparticles is unfavourable to the thermal conductivity of $\mathrm{NaNO}_{3}$ in the studied range. A higher temperature usually leads to a slightly lower thermal conductivity. Fig. 12(b) shows the thermal conductivity of $\mathrm{LiNO}_{3}$ with $15-20 \mathrm{~nm} \mathrm{SiO}$ nanoparticles in the temperature range of 260-300 ${ }^{\circ} \mathrm{C}$. One can see that the introduction of $\mathrm{SiO}_{2}$ nanoparticles all decreases the thermal conductivity compared with the pure $\mathrm{LiNO}_{3}$. What's more, increasing the temperature decreases the thermal conductivity. The pure $\mathrm{KNO}_{3}$ has an average thermal conductivity of $\sim 0.46 \mathrm{~W} / \mathrm{m} / \mathrm{K}$ in the temperature range of $340-380{ }^{\circ} \mathrm{C}$, as shown in Fig. 12(c). The addition of $\mathrm{SiO}_{2}$ nanoparticles from $0.5 \%$ to $4 \%$ gives a decrease in the thermal conductivity.

$\mathrm{SiO}_{2}$ is commonly added in nanofluids as the conductivity enhancer attributing to its high thermal conductivity of $1.3-1.5 \mathrm{~W} / \mathrm{m} / \mathrm{K}$. With the addition of $\mathrm{SiO}_{2}$ in nitrate salts, it is expected to exhibit an

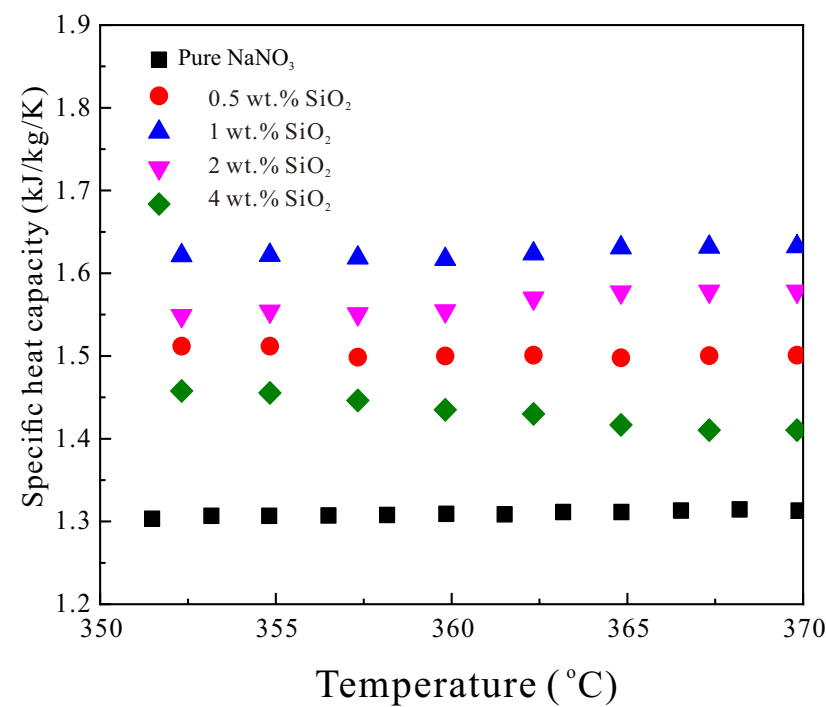

(a)

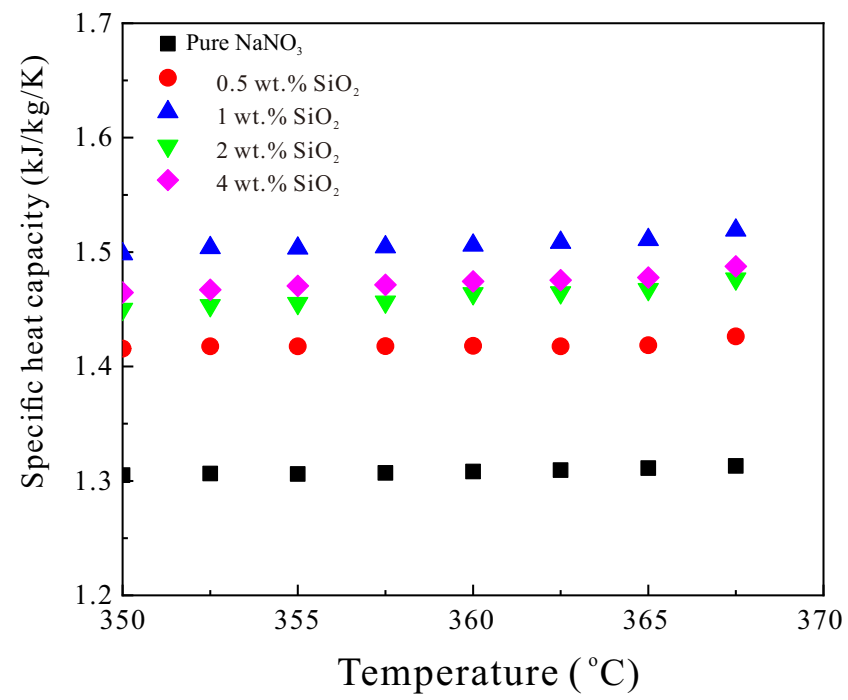

(c)

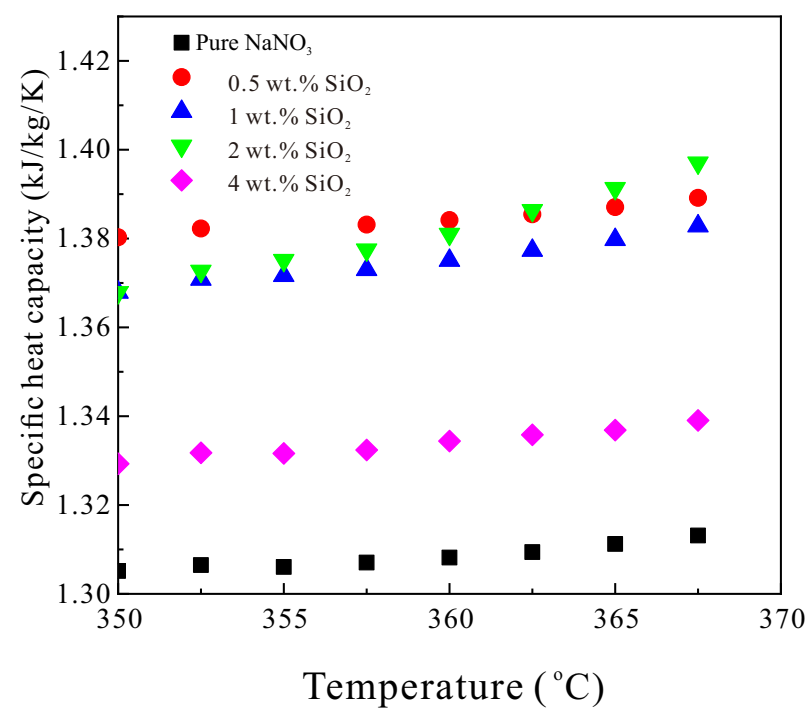

(b)

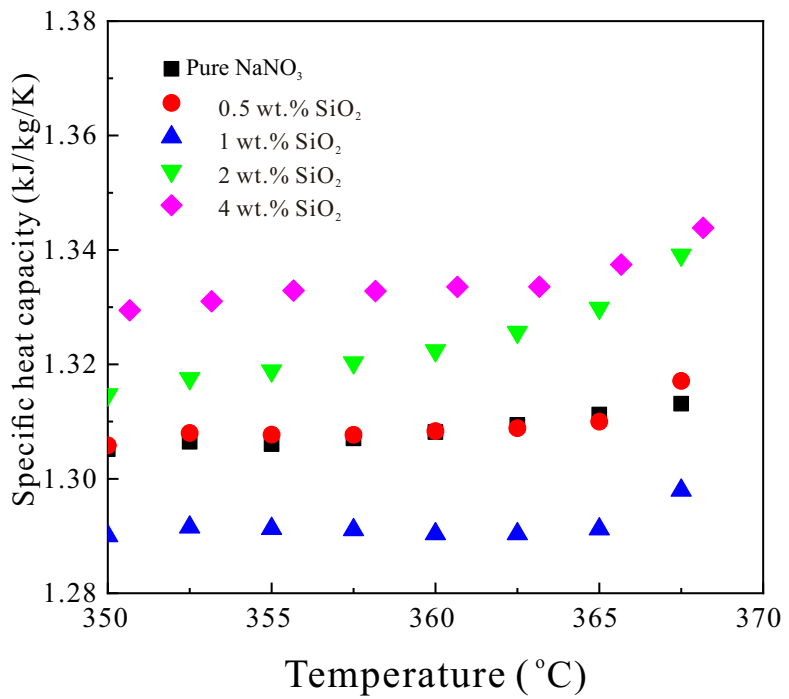

(d)

Fig. 11 Specific heat capacity of $\mathrm{KNO}_{3}$ with various $\mathrm{SiO}_{2}$ particle sizes: (a) $15-20 \mathrm{~nm}$; (b) 20-30 nm; (c) 60-70 nm; (d) 1-5 $\mu \mathrm{m}$. 
enhanced thermal conductivity since $\mathrm{SiO}_{2}$ is more conductive than all nitrate salts. However, the experiment results are against our expectations. A model is hence proposed to help explain this phenomenon, as shown in Fig. 13. Though the thermal conductivity of $\mathrm{SiO}_{2}$ is higher than that of the molten salt, an interfacial layer, existed between the solid $\mathrm{SiO}_{2}$ and the liquid molten salt, provides a much higher thermal resistance, which significantly hinders the heat transfer. The thermal conductivity is then determined by the $\mathrm{SiO}_{2}$ nanoparticles, molten salt and the interfacial layer. This model will be validated from molecular scale in the future work.

\section{Conclusions}

Thermal energy storage (TES) is a powerful technology to shift peak loads of power grids and smooth intermittency of renewable energy. Molten nitrate salts are popular TES materials for solar power plants. However, pure nitrate salts usually show unfavourable properties, which affects the energy storage performance. In this paper, molten nitrate salts based nanofluids are prepared with a novel method. Three popular single salts $\left(\mathrm{NaNO}_{3}, \mathrm{LiNO}_{3}\right.$, and $\left.\mathrm{KNO}_{3}\right)$ are selected as the base salts and $\mathrm{SiO}_{2}$ nanoparticles as the additives. Various parameters, such as $\mathrm{SiO}_{2}$ sizes $(15 \mathrm{~nm}-5 \mu \mathrm{m})$, mass fractions $(0.5-4 \%)$ and working temperatures $\left(200-380{ }^{\circ} \mathrm{C}\right)$, are considered. The thermo-physical properties are experimentally studied, including material structure, melting point, latent heat capacity, specific heat capacity and thermal conductivity. The main conclusions are as follows:
The addition of $\mathrm{SiO}_{2}$ nanoparticles does not change crystallinity of the three nitrate salts and there is no new phase created, which shows agood chemical compatibility between $\mathrm{SiO}_{2}$ nanoparticles and nitrate salts.

The effect of adding $\mathrm{SiO}_{2}$ nanoparticles on melting points of $\mathrm{LiNO}_{3}$ and $\mathrm{KNO}_{3}$ is insignificant. However, for $\mathrm{NaNO}_{3}$, its melting points are decreased by up to $2.5{ }^{\circ} \mathrm{C}$, and a higher mass fraction of $\mathrm{SiO}_{2}$ nanoparticles leads to a lower melting point. The decrease of melting points is probably because the small nanoparticles have a considerable specific surface area and act as nucleation sites, which reduces the free energy required for phase change and hence decreases the melting point.

The latent heat of $\mathrm{NaNO}_{3}$ is decreased or keeps stable with the addition of $\mathrm{SiO}_{2}$ nanoparticles. However, for $\mathrm{LiNO}_{3}$ and $\mathrm{KNO}_{3}$, their latent heat is increased to $\sim 377 \mathrm{~kJ} / \mathrm{kg}$ with 20 - $30 \mathrm{~nm} 1 \%$ $\mathrm{SiO}_{2}$ and $\sim 100.8 \mathrm{~kJ} / \mathrm{kg}$ with $60-70 \mathrm{~nm} 1 \% \mathrm{SiO}_{2}$, respectively.

The introduction of $\mathrm{SiO}_{2}$ nanoparticles enhances the specific heat capacity of the three nitrate salts. For $\mathrm{NaNO}_{3}$ and $\mathrm{LiNO}_{3}$, the highest enhancements of $27.6 \%$ and $12.3 \%$ are observed with the addition of $60-70 \mathrm{~nm} 2 \%$ and $0.5 \% \mathrm{SiO}_{2}$ nanoparticles, respectively. For $\mathrm{KNO}_{3}$, the highest enhancement of $26 \%$ is achieved with $15-20 \mathrm{~nm} 1 \% \mathrm{SiO}_{2}$ nanoparticles. In general, a higher temperature leads to a higher specific heat capacity.

The three nitrate salts exhibit a depressed thermal conductivity with the addition of $\mathrm{SiO}_{2}$ nanoparticles. This is out of expectation

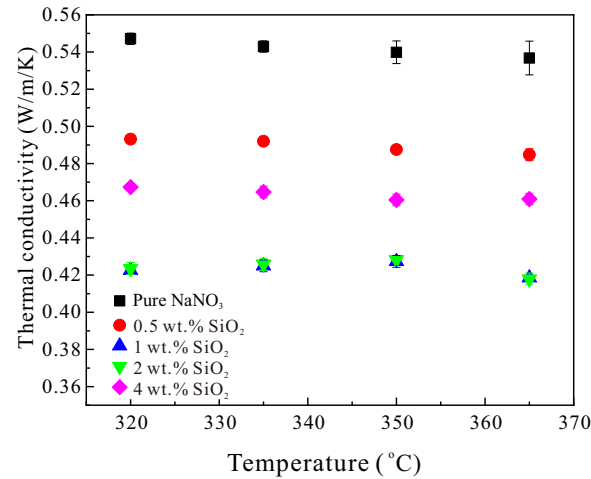

(a)

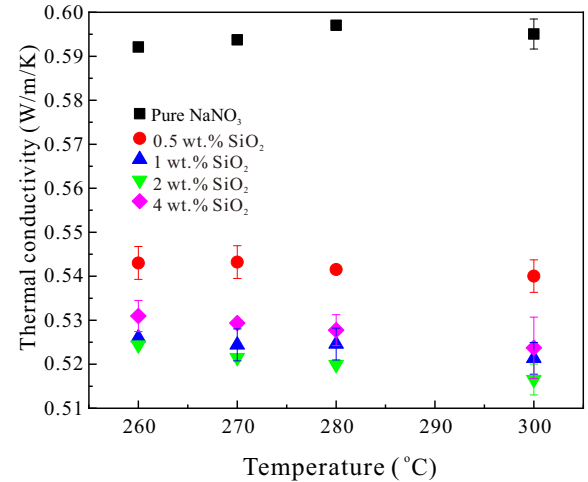

(b)

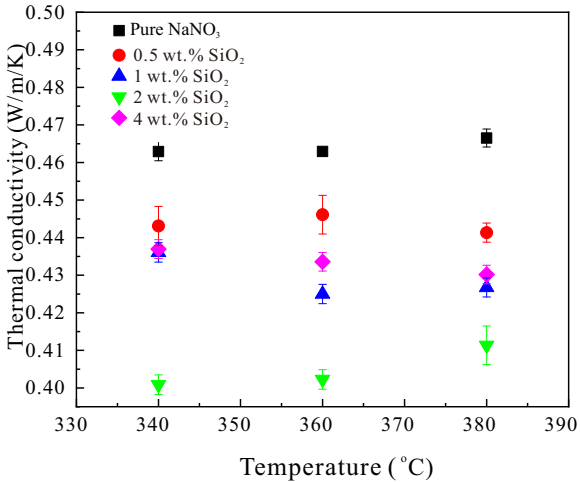

(c)

Fig. 12 Thermal conductivity of (a) $\mathrm{NaNO}_{3}$; (b) $\mathrm{LiNO}_{3}$ and (c) $\mathrm{KNO}_{3}$ with $15-20 \mathrm{~nm} \mathrm{SiO}$ nanoparticles.

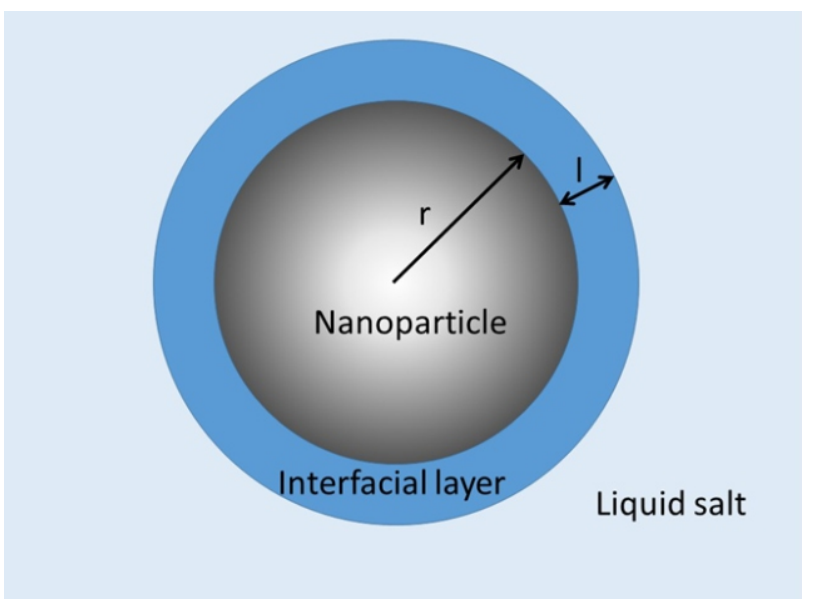

Fig. 13 A nanoparticle with an interfacial layer in a molten salt fluid. 
since $\mathrm{SiO}_{2}$ has a much higher thermal conductivity than the molten salt. It is assumed that there is an interfacial layer between the solid nanoparticle and the liquid molten salt, which provides a much higher thermal resistance and hence decreases the thermal conductivity. This assumption will be validated in the future work from molecular scales.

Finally, $\mathrm{NaNO}_{3}$ with $60-70 \mathrm{~nm} \quad 0.5 \% \quad \mathrm{SiO}_{2}$ nanoparticles is suggested, which enhances the specific heat capacity by $\sim 27 \%$ without affecting the latent heat and thermal conductivity much. For $\mathrm{LiNO}_{3}, 20$ -

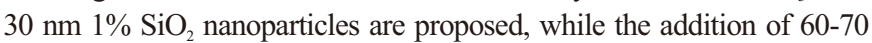
$\mathrm{nm} 1 \% \mathrm{SiO}_{2}$ nanoparticles is recommended for $\mathrm{KNO}_{3}$ which increases the specific heat capacity by $17.6 \%$ and latent heat by $1.6 \%$.

\section{Acknowledgements}

This paper was supported by key technologies for high temperature sensible heat storage using molten salts program from State Grid Corporation of China and Global Energy Interconnection Research Institute Europe GmbH No. SGRI-DL-71-16-018. The authors would like to acknowledge networking support by the COST Action Ca15119.

\section{References}

1. Renewables 2018 Global Status Report, REN21, 2018

2. M. M. Kenisarin, Renew. Sust. Energ. Rev., 2010, 14(3), 955-970.

3. G. Wei, G. Wang and C. Xu , Renew. Sust. Energ. Rev., 2018, 81, 1771-1786.

4. R. I. Dunn, P. J. Hearps and M. N.Wright, Proc IEEE, 2012, 100(2), 504-15.

5. The parabolic trough power plants Andasol 1 to 3, Solar Millennium, (2008) $1-26$

6. G. Xu, G. Leng and C. Yang, Sol. Energy, 2017, 146, 494-502.

7. S. Pincemin , X. Py and R. Olives , J. Sol. Energ., 2008, 130(1):011005.

8. J. Li, W. Lu and Z. Luo, Sol. Energ. Mat. Sol. C., 2017, 171,106-117.

9. J. Li, W. Lu , and Z. Luo, Sol. Energ. Mat. Sol. C., 2017, 159, 440-446.

10. P. Zhang, J. Cheng and Y. Jin, Sol. Energ. Mat. Sol. C., 2018, 176, 36-41.
11. L. L. Zou, X. Chen, Y. T. Wu, X. Wang and C. F. Ma. Sol. Energ. Mat. Sol. C., 2019, 190 ,12-19.

12. X. Li, Y.Wang, S. Wu and L. D.Xie. Energy, 2018, 160,1021-1029.

13. Ángel G. Fernández and J. C. Gomez-Vidal, Renewable Energy, 2017, 101, $120-125$.

14. H. Kim, H. S. Kim, S. N. Lee and J. K. Kim, Int. J. Heat Mass Tran., 2018, 127,465-472.

15. D. Shin, D. Banerjee. Int. J. Heat Mass Tran., 2011, 54, 1064-1070.

16. M. S. Belén, N. M. Javier and I. I. Torres, Renew. Sust. Energy Rev., 2018, 82, 3924-3945.

17. X . Luo, X. Du and A. Awad, Int. J. Heat Mass Tran., 2017, 104, 658-664.

18. P. D. M. Jr, T. E. Alam and R. Kamal, Appl. Energy, 2016, 165, 225-233.

19. A. Awad, A. Burns and M. Waleed, Sol. Energy, 2018, 172,191-197.

20. Y. Hu, Y. He and Z. Zhang, Energ. Convers. Manage., 2017, 142, 366-373.

21. J. Seo and D. Shin, Appl. Therm. Eng., 2016, 102, 144-148.

22. W. Song, Y. Lu and Y. Wu, Sol. Energ. Mat. Sol. C., 2018, 179, 66-71.

23. X. Chen, Y. T. Wu, L. D. Zhang, X. Wang and C. F. Ma, Sol. Energ. Mat. Sol. C., 2019, 191, 209-217.

24. Z. Jiang, A. Palacios, X. Z. Lei, M. E. Navarro, G. Qiao, E. Mura, G. Z. Xu and Y. L. Ding, Appl. Energy, 2019, 235, 529-542

25. G. Qiao, A. Alexiadis and Y. Ding, Powder Technol., 2017, 314, 660-664.

26. G. Qiao, M. Lasfargues, A. Alexiadis and Y. Ding. Appl. Therm. Eng., 2017, 111, 1517-1522.

27. K. Khanafer, F. Tavakkoli and K. Vafai, Int. Commun. Heat Mass, 2015, 69, 51-58.

28. D. Shin, H. Tiznobaik and D. Banerjee, Appl. Phys. Lett., 2014, 104(12), 99105.

29. H. Tiznobaik and D. Shin, Int. J. Heat Mass Tran., 2013, 57(2), 542-548.

30. M. Chieruzzi, G. F.Cerritelli and A. Miliozzi, Sol. Energ. Mat. Sol. C., 2017, 167, 60-69.

31. N. Navarrete, R. Mondragon and D. Wen, Energy, 2019, 167, 912-920.

32. A. Awad, H. Navarro and Y. Ding, Renew. Energ., 2018, 120, 275-288.

33. Y. Grosu, N. Udayashankar and O. Bondarchuk, Sol. Energ. Mat. Sol. C., 2018, 178, 91-97.

Publisher's Note Engineered Science Publisher remains neutral with regard to jurisdictional claims in published maps and institutional affiliations. 